\title{
Changes to the TODS Editorial Board
}

\author{
Richard Snodgrass \\ rtsecs.arizona.edu
}

Mary Fernandez, Raghu Ramakrishnan, and Jennifer Widom rotated off the Editorial Board last month. All have been active on the editorial board, handling dozens of submissions and participating in policy discussions. In particular, Jennifer was a prime architect of TODS' prior publication policy (referred to affectionately as $P^{3}$ ), which has had a salutary effect on papers and on the reviewing process.

We as a community are extremely fortunate that scholars of the stature of Mary, Raghu, and Jennifer are willing to devote hours every week to shepherd submissions through the reviewing cycle thoroughly yet quickly. The Associate Editors, along with the reviewers and authors they work with, are the primary reason that TODS is so prominent.

Thank you, Mary, Raghu, and Jennifer, for your selfless, highly capable work over the last few years.

In other news, the December 2006 issue should be out by the time you read this. This is the muchanticipated SIGMOD/PODS special issue, along with several other regular papers, nine papers in all, another mega-issue.

This issue rounds out the most prolific year in TODS history, with 36 papers in all, five more than the largest of the past thirty volumes. Enjoy! 